C. Nobel | Berlin

\title{
Erratum zu: Unerwünschte Arzneimittelreaktionen in der Mundschleimhaut
}

Die Online-Version des Originalbeitrages ist unter doi: 10.1007/s12614-016-6265-3 zu finden.

In diesem Beitrag wurden leider die Abbildungen 6 und 7 vertauscht.

Die richtige Reihenfolge der Abbildungen ist hier dargestellt:

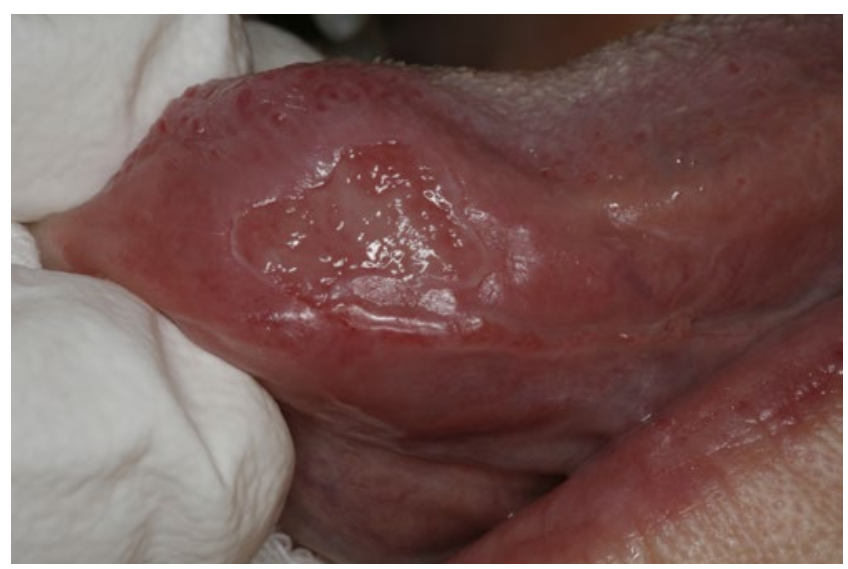

6 orale Ulzerationen durch Methotrexat bei einer Patientin mit rheumatoider Arthritis, drei Jahre nach Therapiebeginn

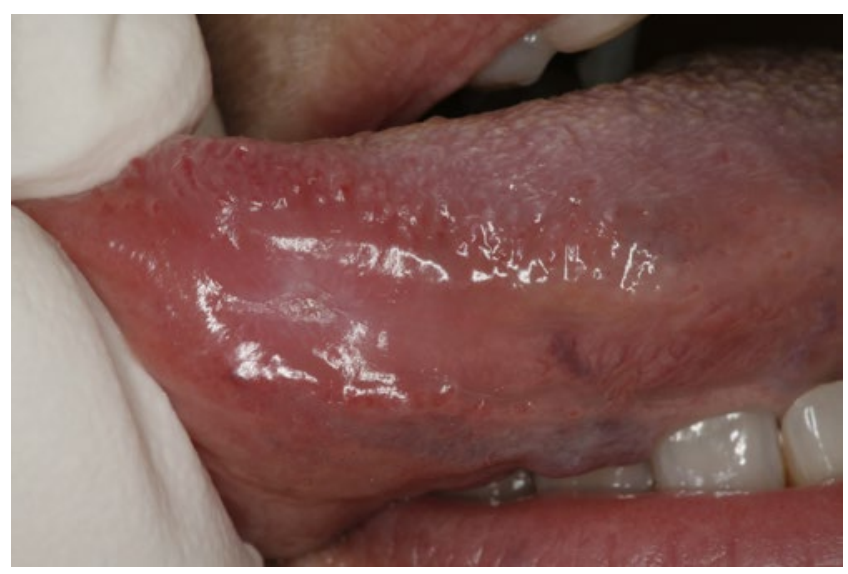

7 Dieselbe Patientin wie Abb. 6: zwölf Tage nach Absetzen der Medikamente, ohne weitere Therapie außer anästhesierender Mundspüllösung
Zudem weisen wir darauf hin, dass die Meldebogen zu unerwünschten Arzneimittelwirkungen zusätzlich zum Abdruck in der Zeitschrit zm - Zahnärztliche Mitteilungen im Internet auf den Seiten der Arzneimittelkommission Zahnärzte bei der Bundeszahnärztekammer unter https://www.bzaek.de/fuer-zahnaerzte/ arzneimittelkommission.html zu finden sind. Dort finden sich auch Hinweise zum Ausfüllen der Berichtsbogen.

Wir bitten, die korrekte Abbildungs-Reihenfolge und den Hinweis zu den Meldebogen zu beachten und den Fehler zu entschuldigen.

Die Redaktion

\section{Korrespondenzadresse:}

\section{Dr. C. Nobel}

Bereich Oralmedizin, zahnärztliche Röntgenologie und Chirurgie CC3 Zahn-, Mund- und Kieferheilkunde

Charité - Universitätsmedizin Berlin

Aßmannshauser Str. 4-6, 14197 Berlin

christiane.nobel@charite.de 